\title{
A FÁBULA GREGA: DA PRÁTICA DISCURSIVA AO GÊNERO LITERÁRIO
}

\author{
Maria Celeste Consolin Dezotti
}

RESUMO: Selon les travaux de Todorov, on établi que le genre littéraire appelé "fable" est la codification des propriétés discoursives propres a une pratique déjà institucionalizée dans la culture grecque. Donc, cet étude montre que ces deux modalités discoursives, qui existent encore aujourd'hui, constituent deux diférents états de la fable, avec des conséquences particulières pour les structures des enoncés de chaque modalité. D’abord, on analyse la structure des textes ésopiques anonymes; ensuite, on examine des textes d' Hérodote, Hésiode et, enfin, on arrive a Homére, qui nous donne des éléments pour confirmer l'hypotése selon laquele le schéma discoursive qui est à l'origine de la fable comme genre litéraire était déja institué comme pratique linguistique dans le monde des héros homériques.

PALAVRAS-CHAVE: fábula, argumentação, epimítio, promítio, enunciado, enunciação, fórmula, Esopo, Homero, Heródoto.

Quando se analisam as fábulas esópicas das coleções anônimas levando-se em conta a sua instância de enunciação, observa-se que ela é um discurso, um ato de fala, que se realiza pela articulação de três discursos: um discurso narrativo, um interpretativo ou moral, e um pragmático ou metalingüístico. Vejamos como esses componentes podem ser identificados, a título de ilustração, na fábula "O lobo e o cordeiro":

Um lobo viu um cordeiro bebendo água de um rio e desejou devorá-lo por um motivo qualquer bem pensado. Por isso, tendo-se postado mais acima, pôs-se a acusá-lo de turvar a água e de impedi-lo de beber. O cordeiro, então, disse que estava bebendo com a ponta dos lábios e que, além do mais, não podia ser que ele, estando mais abaixo, estivesse turvando a água do lado de cima. E o lobo, tendo perdido nessa acusação, disse: "Mas no ano passado você injuriou meu pai!" E como o cordeiro dissesse que naquela época nem era nascido, o lobo the falou: "Mesmo que você se saia bem na defesa, eu não vou deixar de lhe comer!"

A fábula mostra que junto daqueles cujo propósito é praticar a injustiça, nem uma justa defesa prevalece'.

Como toda fábula esópica, essa também se organiza em dois parágrafos: no primeiro, está a narrativa, e, no segundo, o epimítio, assim chamado pelos retores antigos justamente porque vem depois da narrativa (mythos). O epimítio, por sua vez, se constitui de um texto moral ("junto daqueles cujo propósito é praticar a injustiça, nem uma justa defesa prevalece") e de um texto metalingüístico ${ }^{2}$, que, sintaticamente, é representado pela oração principal: "a fábula mostra".

Esse enunciado "a fábula mostra" precisa ser decodificado, para que se perceba sua verdadeira estrutura enunciativa subjacente. Na estrutura de superfície, institui-se o mythos como sujeito do ato de mostrar que o verbo lhe predica. Ora, a própria condição de enunciado que está na essência de mythos pressupõe a existência de um locutor que o enuncia. Vemos, pois, que a estrutura sintática do enunciado metalingüístico camufla sua estrutura semântica: quem mostra mesmo é o locutor, que se serve de uma

Maria Celeste Consolin Dezotti é professora da Faculdade de Ciências e Letras, Unesp/Araraquara, SP

${ }^{1}$ Todas as traduções de textos gregos apresentadas neste trabalho são de minha autoria.

2 Adoto o esquema descritivo e a terminologia fixados por Alceu Dias Lima (1984). 
narrativa (mythos) como instrumento de demonstração. Por implicação, recupera-se também o alocutário, pois toda enunciação visa a um destinatário. Assim, como expediente retórico, o locutor se esconde atrás de seu próprio enunciado, sem, contudo, apagar todas as marcas de sua enunciação.

Por meio do enunciado metalingüístico, hierarquicamente o mais alto — pois é ele que articula o enunciado narrativo com o enunciado moral —, o destinador da fábula indica ao destinatário a força ilocutória (mostrar, ensinar, recomendar, etc.) de seu ato de fala. Esse enunciado se expressa, na fábula grega, por construções formulares ${ }^{3}$., de fácil memorização. Assim, muitas vezes, o fabulista considerava suficiente apresentar apenas uma parte da fórmula, certo de que seu interlocutor tinha competência para preencher as lacunas deixadas. Por exemplo: a fórmula a fábula mostra, a mais empregada nas fábulas anônimas, aparece indicada, com freqüência, pela presença da conjunção integrante que (hóti em grego). ${ }^{4}$

Nas coleções esópicas, discursos interpretativos e discursos metalingüísticos se organizam em forma de epimítios. Logo, é necessário considerá-lo, na organização discursiva da fábula, tão importante quanto o texto narrativo, pois ele é o espaço onde as propriedades discursivas do gênero se concretizam por meio de enunciados.

Deve-se, portanto, considerar a fábula esópica anônima como documento de um estágio da história da fábula em que ela já se encontrava fixada como um gênero discursivo composto de texto narrativo acompanhado de epimítio. Afinal, o estilo formular e as construções elípticas constituem provas decisivas de que o epimítio esteve, necessariamente, sempre presente, como seu componente integrante e fundador, no processo de fixação da fábula como gênero literário.

Segundo Todorov (1980, p. 48), os gêneros do discurso existem, numa dada sociedade, como instituição, responsável pela codificação de propriedades discursivas que funcionam como normas que controlam a produção e a recepção de textos por parte dos indivíduos dessa sociedade. Assim, um gênero literário ou não, nada mais é do que essa codificação de propriedades discursivas. E, muitas vezes, observa ele, os gêneros coincidem com atos de fala que também têm existência não literária numa dada sociedade. Tais considerações de Todorov nos estimulam a reexaminar um conjunto de narrativas que aparecem encaixadas em discursos no interior de obras da literatura grega, como a epopéia homérica, por exemplo, e que, apesar de apresentarem um funcionamento discursivo idêntico ao da fábula esópica, não são consideradas como fábulas pela maioria dos estudiosos. $\mathrm{O}$ que se pretende mostrar é que esses textos constituem, sim, documentos da fábula enquanto prática discursiva. Eles representam aquele estágio do gênero discursivo pressuposto, segundo Todorov, para a sua institucionalização como gênero literário. Confrontadas com eles, as fábulas esópicas são o testemunho da sistematização de um gênero correspondente a um tipo de ato de fala que teve existência não literária na Grécia Antiga, e que acrescente-se - ainda mantém-se vivo em nossa cultura. Distinguiremos, pois, daqui por diante, duas realidades textuais: a fábula literária, texto autônomo que institui seu próprio contexto por meio de epimítios, tal qual a documentam as coleções esópicas, e a fábula encaixada, aplicada a uma dada situação discursiva por um locutor que decidiu construir seu ato de fala por meio de uma narrativa. Para a discussão dessa última modalidade, selecionamos textos de Heródoto, de Hesíodo, e de Homero, o mais antigo de todos.

\section{A PRÁTICA DA FÁBULA}

Vejamos em Heródoto dois testemunhos extremamente interessantes para o estudo da prática da fábula. Heródoto conta que no tempo em que os jônios e os eólios eram súditos de Creso, rei da Lídia, Ciro lhes propôs que se rebelassem contra o domínio lídio e se submetessem aos persas. Inicialmente os gregos se recusaram a fazê-lo, mas reconsideraram a proposta assim que Ciro subjugou o império lídio. Então mandaram embaixadores a Sardes oferecendo-se para ser súditos da Pérsia nas mesmas condições de que desfrutavam quando estavam sujeitos a Creso. Segundo Heródoto, a resposta que Ciro lhes enviou foi a seguinte narrativa:

\footnotetext{
${ }^{3}$ Para uma descrição minuciosa dos tipos de fórmulas e de sua função coesiva nas fábulas, cf. Dezotti, 1992/1993, p. 117-132.

4 Um exemplo dessa elipse é o epimítio da fábula "O Sol e as Rãs" (Esopo 127) que se apresenta assim: "Que muitas pessoas que têm espírito leviano acham graça no que não tem graça”.
} 
um flautista avistou peixes no mar e pôs-se a tocar a flauta, crente de que assim os atrairia para a terra. Frustrado em sua esperança, apanhou uma rede, pescou uma grande quantidade de peixes e puxou-os para fora. E quando viu que eles davam saltos, disse-lhes: "Parem com essa dança, pois vocês não quiseram sair para dançar quando eu tocava a flauta." $(\mathrm{I}, 141)^{5}$.

E os jônios, que interpretaram corretamente a mensagem da narrativa de Ciro, trataram de fortificar suas cidades com muralhas, pois lhes tinha sido negada a possibilidade de submissão pacífica.

Esse é um exemplo de fábula encaixada cuja força ilocutória não se expressa em um enunciado, mas se manifesta na própria situação discursiva. Heródoto recompõe o contexto em que Ciro praticou a fábula. Há aí um locutor (Ciro), alocutários (jônios e eólios), um discurso anterior (a proposta dos gregos) e um discurso subseqüente (a interpretação que os gregos fizeram da narrativa). Considerando-se que o discurso que precede a narrativa é uma proposta, a narrativa de Ciro é recebida como resposta àquela proposta. Ciro, portanto, leva em conta a expectativa de resposta, por parte de seus interlocutores, e lhes responde por meio de um lógos, como diz Heródoto. Uma vez fixado pela própria situação discursiva que a narrativa valia como resposta, Ciro delega aos seus interlocutores a tarefa de interpretá-la. Coube a eles, portanto, compor o epimítio da fábula, dela extraindo a interpretação que faltava para completar o esquema discursivo da fábula.

O segundo exemplo que comentaremos, também extraído de Heródoto, difere do anterior por apresentar, como texto narrativo, um relato de fatos apresentados como verídicos pelo locutor. Veremos, porém, que mesmo assim ele preenche todos os requisitos para que seja considerado uma fábula na condição de prática discursiva.

Heródoto conta que Eutiquides, rei de Esparta, havia deixado alguns reféns sob guarda em Atenas. Quando, porém, foi buscá-los, os atenienses se recusaram a devolvê-los. Diante disso, Eutiquides lhes relata um fato ocorrido em Esparta a propósito de uma entrega em confiança: trata-se da história de Glauco, um espartano que teria vivido duas gerações antes da sua, famoso como homem justo, a quem um cidadão de Mileto confiara em depósito uma certa quantidade de moedas de ouro. Na hora de devolvê-la ao dono, Glauco se recusa a fazê-lo e, alegando que não se lembrava de ter assumido tal compromisso, vai consultar o oráculo sobre a possibilidade de reter o dinheiro sob falso juramento. Como lhe fosse dito que pôr o deus à prova e praticar a deslealdade eram faltas iguais, Glauco, apressa-se em restituir o depósito. E Eutiquides completa:

O porquê de essa história ter sido narrada a vocês será dito: de Glauco atualmente não existe um só descendente, nem um lar que se possa considerar seu. Ele foi extirpado de Esparta até a raiz. Assim, é bom não pensar em outra coisa quando se trata de um depósito em confiança, senão em restituir o que é reclamado. (VI, 86)

Há, nessa passagem, uma situação discursiva perfeitamente delineada: Eutiquides, o locutor, enuncia aos atenienses, seus alocutários, uma longa história, um lógos, como ele diz, seguido de um epimítio introduzido por "assim" (hoúto, em grego), que também integra a lista de fórmulas metalingüísticas encontradas nos epimítios das fábulas literárias. Nesse caso, é o próprio locutor que interpreta a narrativa para seus interlocutores, apresentando-a como recomendação.

Essas duas ocorrências de fábula aplicada nos permitem propor que, para que se pratique uma fábula, não é necessário que a narrativa seja de natureza ficcional, nem que seja uma narrativa curta. Basta apenas que seja uma narrativa ${ }^{6}$.

Entendendo-se como funcionam os atos de fala que se realizam por meio de narrativas, é possível analisar como fábulas textos bem mais antigos que os de Heródoto, o que nos prova que, pelo menos desde a época arcaica, a fábula já existia na Grécia como prática discursiva corrente, institucionalizada como uma alternativa para a elaboração de atos de fala.

É praticamente consensual, entre os estudiosos, que está em Hesíodo o primeiro exemplo de fábula grega aplicada a uma situação ${ }^{7}$. O critério para essa classificação é a natureza da narrativa, cujas personagens são representadas por animais, o rouxinol e o gavião ${ }^{8}$, segundo o tipo de narrativa predominante nas fábulas esópicas. Após o relato do mito das raças, Hesíodo diz assim:

Agora vou contar um caso aos reis, a eles, os sábios.

Assim falou um gavião a um rouxinol de pescoço malhado, levando-o para bem alto, nas nuvens, preso nas garras;

\footnotetext{
${ }^{5}$ Cf. a versão esópica dessa fábula em Chambry (1927), fábula 24.

${ }^{6}$ Nojgaard (1964:505) classifica essa fala de Eutiquides de "conto ficcional" seguida de epimítio. Mas, para ele, o epimítio não é constitutivo da fábula.

${ }^{7}$ Cf. Chambry (1927, p. xxii), Nojgaard (1964, p. 442), Adrados (1982, p. 43).

${ }^{8}$ Cf. a versão esópica dessa fábula em Chambry (1927) fábula 8.
} 
ele, que, miserável, trespassado por garras recurvas, gemia. A ele o prepotente proferiu tais palavras:

"Demônio, por que gritas? Pertences a um mais forte!

Irás onde eu te levar, cantor que sejas.

Se eu quiser, farei de ti refeição ou te soltarei.

Louco é aquele que pretende resistir aos mais fortes!

Frustra-lhe a vitória e, além do opróbrio, mágoas suporta.

Assim falou o gavião, de vôo veloz, pássaro de asas abertas.

Tu, ó Perses, ouve a justiça! Não fomentes a desmesura.

A desmesura é um mal para o homem pobre. E nem o grande

consegue fácil suportá-la. Antes, sob ela esmaga-se,

ao chocar-se com desgraças. O caminho que leva pelo outro lado

a atos justos é melhor. A justiça vence a desmesura,

quando chega o momento. Sofrendo é que o tolo aprende. (202-218)

As informações que delineiam o contexto da enunciação dessa fábula precedem o texto narrativo. Dizemos, portanto, que elas estão expressas em promítio. Particularizada como enunciado destinado a reis, a fábula de Hesíodo se destina também a Perses, o irmão do poeta, que se mancomunara aos reis para tomar do poeta a parte da herança que por direito lhe cabia. Por isso, o texto narrativo vem acompanhado também de um epimítio, em que o poeta se permite interpelar tanto Perses como os reis, e exortá-los a ouvir a justiça. Como o rouxinol da fábula, cuja vida estava nas mãos do gavião, também o poeta dependia do querer dos mais fortes.

Nojgaard (1964, p. 446) observa que Hesíodo adaptou um texto que já existia às necessidades do contexto de sua obra. É que a versão esópica dessa fábula narra a ação do falcão até o fim: ele decide que o rouxinol deve morrer e, ao contrário de Hesíodo, sanciona positivamente essa decisão. Afinal, o falcão teria se mostrado previdente em decidir alimentar-se com o que havia ao seu dispor. Hesíodo, ao contrário, repelindo essa possibilidade de interpretação, constrói para o seu texto um longo epimítio que fixa a linha de interpretação da narrativa. Se, conforme Perses poderia interpretar, no plano dos homens, a vida do fraco está nas mãos do forte, sobre os dois, forte e fraco, paira um mais forte ainda, a Justiça, nascida de Zeus. Segundo a orientação do locutor, o falcão deve ser interpretado como representação alegórica da Justiça, e o rouxinol, como representação alegórica deles próprios, os reis e Perses.

O que o exemplo de Hesíodo nos indica é que sua narrativa só tem seu sentido definido depois que o epimítio fixa o modo como ela deve ser interpretada. A partir dessas indicações, retoma-se o texto narrativo e interpreta-se a alegoria que ele representa ${ }^{9}$. É evidente, então, que a fábula, mesmo na condição de fábula aplicada a uma dada situação, resulta do ato de se dotar um texto narrativo de um determinado significado. Essa é a estrutura básica do ato de fala que caracteriza a fábula, seja como gênero literário, seja como prática discursiva.

Com base, pois, nesse esquema discursivo, é possível remontar a Homero e considerar como prática discursiva da fábula muitos dos discursos proferidos pelos heróis. Na Ilíada, por exemplo, vemos o próprio Aquiles a praticar uma fábula, quando narra a Príamo o mito de Níobe, com a intenção de convencê-lo a superar a aflição pela morte de Heitor e a aceitar a refeição que lhe estava sendo ofertada. Depois de concordar em devolver o cadáver de Heitor ao velho Príamo, Aquiles lhe diz:

teu filho está resgatado, velho, como pediste,

ele jaz no leito. Tão logo brilhe a aurora,

tu o verás, ao levá-lo. Agora, porém, pensemos na ceia,

pois até Níobe de belos cabelos pensou em comida,

mesmo quando seus doze filhos no palácio pereceram,

seis filhas e seis filhos na flor da idade.

A esses Apolo matou com o arco de prata,

irado com Níobe, e a elas matou Ártemis frecheira,

porque a mãe competia com Leto de formoso rosto:

esta concebera dois, dizia, e ela dera à luz a muitos.

Mas esses, dois que eram, todos os doze dizimaram.

Nove dias jazeram no sangue, sem que alguém

os sepultasse, pois o povo em pedras o Cronida convertera;

só no décimo dia sepultaram-nos os deuses celestes.

\footnotetext{
${ }^{9}$ Hesíodo nomeia ainos essa narrativa. A tradução "caso" não dá conta do sentido pleno da palavra. Ainos é relato, mas "relato de palavras veladas", conforme podemos deduzir do verbo cognato ainíssomai "dizer por meio de palavras veladas". Outro cognato importante para se delimitar o sentido preciso de ainos nesses versos de Hesíodo é aínigma, "palavra obscura", "enigma".
} 
Aí então de comer lembrou-se ela, cansada de verter lágrimas.

Agora, em algum lugar rochoso, em montes desolados,

no Sípilo, onde dizem haver moradas de deusas

ninfas, que bailam às margens do Aquelôo;

lá, em forma de pedra, ela digere o castigo divino.

Mas vamos, divino ancião, cuidemos de nosso

alimento! Então poderás prantear o filho querido,

após o traslado para Ílion. Muitas lágrimas terás de verter. (XXIV, 599-620)

Compare-se, a propósito, essa fala de Aquiles com uma fala de Ulisses, também na Ilíada, sobre o mesmo tema, e numa situação parecida. Pátroclo está morto e Aquiles, impaciente por vingar a morte do amigo, quer empreender imediatamente uma batalha. Ulisses, para convencê-lo de que primeiro era necessário oferecer-se alimento aos guerreiros, profere o seguinte discurso:

não com o ventre devem os Aqueus trazer luto por um morto.

em número excessivo todos os dias tombam eles

cerrados. Quando se terá algum alivio na fadiga?

É mister dar sepultamento àquele que morre,

mantendo firme o ânimo, após um dia de pranto.

E quantos à pavorosa batalha sobrevivermos,

lembremo-nos de beber e de comer, para ainda melhor

combatermos contra homens hostis, sempre, sem cessar,

nossos corpos revestidos de bronze indestrutível. (XIX, 225-233)

Esses discursos ilustram duas formas de argumentação completamente diferentes. Enquanto a de Aquiles se constrói com um texto narrativo alegórico, a de Ulisses é de natureza dissertativa. A fala de Aquiles, portanto, só difere da fábula esópica dado o tipo de narrativa que a estrutura. Aquiles, como todos os demais heróis de Homero que falam por meio de fábulas, usa narrativas míticas que relatam episódios vivenciados ou por eles próprios, ou por outros heróis, ou então pelos deuses. Ou seja, como eles são heróis, selecionam narrativas que falem de seus iguais, também heróis, ou então de seus superiores, os deuses. Essa preferência, porém, possivelmente ditada pela própria condição aristocrática do herói, em nada afeta a estrutura discursiva do texto, que, como se pode notar, é uma legítima fábula aplicada. Em vez de se pensar, como Nojgaard (1964, p. 449), que Homero não usou em seus poemas a fábula (isto é, aquele tipo de narrativa predominante nas coleções esópicas anônimas) porque ela era de natureza anti-aristocrática e anti-idealista, preferimos pensar o inverso: Homero traz a fábula para dentro da epopéia, fazendo seus heróis falarem por meio de narrativas, mas ajusta os textos narrativos à ideologia aristocrática das personagens.

Conclui-se, portanto, que, para praticar uma fábula, o falante grego podia optar por qualquer tipo de narrativa, fosse ela curta ou longa, ficcional ou não. Bastava que fosse uma narrativa. Além disso, ele tanto podia explicitar os três discursos que compõem o esquema discursivo canônico da fábula — narrativo, metalingüístico e interpretativo —, como podia explicitar apenas o narrativo, que é o especificador do gênero, deixando implícito o metalingüístico, ou o interpretativo, ou ambos ao mesmo tempo. A elipse de um ou outro discurso dependia das próprias características da situação em que a fábula era praticada, e também das intenções lúdicas do locutor.

Da fábula como gênero discursivo já institucionalizado na cultura grega como um ato de fala realizado por narrativas é que deriva a fábula como gênero literário. Esta, porém, ao contrário da prática discursiva, não permitia ao locutor valer-se dos fatores situacionais para indicar ao interlocutor o valor ilocucional da narrativa. Isso porque a fábula autônoma instaura, pela própria linguagem, sua própria situação discursiva. Por isso é necessário pressupor-se que, quando se torna gênero literário, a fábula se institucionaliza com um esquema discursivo canônico que prevê a explicitação, em promítios ou em epimítios, do modo como o texto narrativo deve ser interpretado pelo alocutário ${ }^{10}$.

Assim, num primeiro momento de sua história, a fábula autônoma deve ter explicitado no mínimo o seu discurso metalingüístico, pois é nele que o locutor indica o valor de sua enunciação. É só a partir da institucionalização desse esquema canônico — também constituído de discurso narrativo, metalingüístico e interpretativo, como o da fábula aplicada —, que se pode explicar a condição de fábula de certos textos que omitem um ou mais desses constituintes. Nesse caso, é possível ao alocutário preencher o esquema discursivo canônico valendo-se das relações intertextuais que se estabelecem entre

\footnotetext{
${ }^{10}$ A fábula esópica anônima mostra exclusiva preferência pelo epimítio. Já as fábulas de Fedro se estruturam ora com promítios, ora com epimítios. Mas é a tradição esópica que tende a dominar na fábula ocidental.
} 
as fábulas. Considerando-se tais relações, o alocutário consegue identificar o discurso elíptico e realizá-lo, tornando-se, desse modo, co-elaborador do texto da fábula (Suleiman, 1977, p. 475).

O esquema canônico da fábula literária prevê, ainda, que se use narrativas ficcionais. Verifica-se, conseqüentemente, a preferência por narrativas de animais, que passam a ser predominantes no gênero, sem, contudo, excluir outras tipologias como a anedota, a etiologia e o mito.

Adrados (1982, p. 34) lembra que a fábula é um gênero especialmente constante. Tanto pode apresentar alguma alteração de forma, como pode ajustar o seu conteúdo às circunstâncias, mas não deixa de pertencer aos níveis populares da literatura, que são muito mais fixos e conservadores do que as grandes criações. De fato, um exame, ainda que superficial, de algumas coleções de fábulas modernas, mostra que a fábula literária preserva, como possibilidades de estruturação de textos, todos os tipos de narrativas usados pela fábula grega anônima. Escritores como Millôr Fernandes e o guatemalteco Augusto Monterroso continuam a construir suas fábulas, servindo-se de anedotas, mitos, etiologias, etc., presos que estão ao modelo discursivo de fábula consagrado no Ocidente pelas coleções esópicas anônimas.

Há que se dizer, ainda, que o recorte feito entre prática discursiva e gênero literário é válido também para o estudo da fábula moderna. Esta continua a existir em sua modalidade literária, que muitas vezes reelabora velhas fábulas esópicas. Mas, o que é interessante é que essa modalidade literária convive ainda hoje com a modalidade da fábula aplicada, como nos velhos tempos dos gregos. Vejamos alguns exemplos.

O primeiro está na famosa conferência "Lingüística e Poética", de Roman Jakobson (1975: 161), em que ele, ao discutir a poeticidade dos elementos que compõem a poesia, intercala, em suas considerações, esta fábula:

Um missionário censurou seu rebanho africano por andar despido. 'E o senhor?', responderam os nativos, apontando-lhe para o rosto, 'não anda despido em alguma parte?' 'Bem, mas é meu rosto.' 'Pois bem', retorquiram os nativos, 'conosco, tudo é rosto'. Assim também, em poesia, qualquer elemento verbal se converte numa figura do discurso poético.

O segundo exemplo de prática da fábula foi extraído de uma entrevista concedida pelo violinista russo Vladimir Spivakov ao jornal Folha de São Paulo (13.11.88, E-3). Quando o repórter lhe perguntou se ele acreditava já ter atingido a harmonia entre o coração e a mente, Spivakov lhe respondeu:

Quando tinha 80 anos, o pintor Ko Ku Sai disse que só então começava aprender como pintar as folhas das árvores. Disse que esperava, em outros dez anos, aprender a pintar os galhos da árvore. E em outros dez a árvore completa. Com isso ele mostrava que são necessários muitos anos e muito esforço para se conseguir a harmonia, mesmo quando se quer retratar algo aparentemente tão simples como uma árvore. É necessário tentar. O resultado não é garantido. Estou tentando.

Esses dois exemplos de fábula encaixada sugerem que muitas das características da prática da fábula na Grécia Antiga persistem ainda hoje. Vejam-se, por exemplo, os epimítios: nos dois casos, os locutores expressam o discurso metalingüístico por meio de itens gramaticais (assim também, no texto de Jakobson, e isso, no texto de Spivakov). O interessante é que esses dois itens correspondem exatamente aos significados das fórmulas hoúto kaí e toûto, respectivamente, documentadas nas fábulas esópicas.

Uma outra característica diz respeito aos textos narrativos. Jakobson usa uma narrativa ficcional — uma anedota — , enquanto Spivakov faz um relato de fatos apresentados como verídicos. Nota-se, contudo, que a distinção entre ficção e não-ficção continua não sendo pertinente para a fábula aplicada. Esses traços se anulam. Na verdade, nenhum leitor vai conferir se o pintor Ko Ku Sai existe mesmo e se ele realmente disse o que Spivakov relatou que ele havia dito. Importa apenas o fato narrado a seu respeito. E é essa narrativa que cumpre uma função na situação discursiva em que é enunciada.

\section{BIBLIOGRAFIA}

ADRADOS, Francisco Rodrigues. Estudio sobre el léxico de las fábulas esopicas. Salamanca, Consejo Superior de Investigaciones Cientificas, 1948.

ADRADOS, Francisco Rodrigues. La fabula griega como genero literario. In: DELGADO, J.A.F. (ed.) Estudios de forma y contenudo sobre los generos literarios griegos. Cáceres, Universidad de 
Extremadura, 1982, p. 33-46.

BENVENISTE, Émile. Le vocabulaire des institutions indo-européenes. v. 2. Paris, Minuit, 1969, p.133-142.

CHAMBRY, Émile. Ésope. Fables. Paris, Les Belles Lettres, 1927.

DEZOTTI, Maria Celeste Consolin. A significação das estruturas formulares nos epimítios da fábula esópica anônima. In: Clássica. São Paulo, v. 5/6, p. 117-132, 1992/1993.

HÉSIODE. Les travaux et les jours. Texte établi et traduit par P. Mazon. Paris, Les Belles Lettres, 1928. HÉRODOTE. Histoires. Texte établi et traduit par Ph. E. Legrand. Paris, Les Belles Lettres, 1948.

JAKOBSON, Roman. Linguística e poética. In: Linguística e comunicação. Traduzido por Izidoro Blikstein e José Paulo Paes. 8a. ed. São Paulo: Cultrix, 1975.

LIMA, Alceu Dias. A forma da fábula. In: Significação. Araraquara, v. 4, 1984. p. 60-69.

NOJGAARD, Morten. La Fable antique. Tome Premier. Kopenhaguen, Nyt Nordisk Forlag, 1964.

SULEIMAN, Susan. Le récit exemplaire. Parabole, fable, roman à these. In: Poétique. Paris, v. 32, p. 468-

489, 1977.

TODOROV, Tzvetan. Os gêneros do discurso. Traduzido por Elisa A. Kossovitch. São Paulo, Martins

Fontes, 1980.

Organon, Porto Alegre, nº 27, julho-dezembro, 1999, p. 137 - 146 